Jan Nab ${ }^{\mathrm{I}}$, Albert Pilot $^{\mathrm{I}}, \mathrm{S}$. Brinkkemper ${ }^{\mathrm{II}}$, Hanne ten Berge ${ }^{\mathrm{I}}$

\title{
Authentic competence-based learning in university education in entrepreneurship.
}

I. Corresponding address: IVLOS Institute of Education, Utrecht University, POBox

| 80127, 3508 TC Utrecht, Netherlands. E-mail: j.nab@ivlos.uu.nl, a.pilot@ivlos.uu.nl and j.h.tenberge@ivlos.uu.nl

II. Department of Information and Computing Sciences, Utrecht University, POBox 80089, 3508TB Utrecht, Netherlands; s.brinkkemper@cs.uu.nl

\section{Summary}

In this paper we present the concept of authentic learning as an integrated part of competence-based learning in entrepreneurship education, focusing on the relevance of this conceptual framework for education in entrepreneurship. The principles of authentic learning have led to a set of design principles for entrepreneurship education for science students. Design principles can help in describing interventions in education in entrepreneurship in forthcoming studies.

\section{Introduction}

During the last decades several theoretical perspectives on entrepreneurship have succeeded ${ }^{1}$, and the theoretical perspectives on education in entrepreneurship has strongly been influenced by these theories. Stevenson and Sahlman ${ }^{2}$ identified three successive perspectives: the economic perspective, the personality perspective and the behavioral perspective. In the nineties the personality perspective has been criticized and research has moved from "who" entrepreneurs are, towards "what" they do ${ }^{3}$. Also more 
emphasis is given to the context in which entrepreneurs operate. Rae ${ }^{4}$ considers entrepreneurship as a contextual process of becoming in which the entrepreneur is permanently learning and developing in relation to himself and his environment. Recently attention is focused on the cognitive aspects of entrepreneurship and learning ${ }^{5,6}$. The concept of competences as it was developed in vocational education, and now being accepted in higher education, accumulates the personality and behavioral perspectives, the context as learning environment and the cognitive approach of entrepreneurship: it is the synthesis of knowledge, skills, attitudes and personal qualities for the performance of specific, professional tasks ${ }^{7}$. Competence-based learning is stimulated in a learning environment, that is functional, realistic, activating, coaching, and inviting to learn. Such a learning environment can be designed with the aid of the theory of authentic learning. The authenticity of tasks refers to the degree of similarity between the task used in an educational setting and those tasks in a real professional setting (type of problems, constraints, information, materials and other resources), or the extent at which they require processes and activities similar to those in a real setting, with similar timeframes ${ }^{8,40}$. This study aims at the verification of a set of design principles ${ }^{9}$ for entrepreneurship education for science students at university level, based on the theory of authentic learning. The design principles of authentic learning this paper are deduced from a primary design of a course in entrepreneurship in ICT at Utrecht University in the Netherlands. This course was evaluated in its outcomes in starting ventures, learning effects and perception of students. Based on the evaluation results the design principles were adjusted and new principles were added.

\section{Authentic learning}

Projects, cases, and problems have frequently been used in higher education as a starting point for learning. A real problem coupled with a future professional situation and context are key features of an "authentic" problem ${ }^{10}$. Our decision to design authentic tasks aims at engaging students in that typical same sort of problem solving, reasoning and decision making processes that is characteristic for the professional practice. According to the situated cognition paradigm, it is important that learning is contextualized: problem solving is a domain and context specific task ${ }^{11,12}$. Problem solving requires domain specific knowledge, both declarative and procedural ${ }^{13}$. The knowledge is general and explicit (concepts, models, principles, methods and procedures, etc.). Also tacit knowledge is involved in problem solving, often specific for a group of problems or contexts.

Ten Berge et. al ${ }^{14,39,40}$ analyzed which aspects of authenticity have influence on students in learning about entrepreneurship in the development of product software. It was noticed that the design of authentic tasks could be described in six groups of design features: Working atmosphere: By introducing elements of an authentic working atmosphere students learn to work in circumstances that they will encounter in practice and will thereby be stimulated in an effective attitude.

Student in the role of problem solver: Student should have a function in activities comparable to that in professional situations. This means that they get enough autonomy and responsibility to accomplish the task.

Type of problems and activities: Students should work on tasks and problems, as they occur in the professional life of the entrepreneur. Students should experience these tasks 
as real and meaningful. Problems delineated from the daily practice in the domain should be transformed to instructionally feasible tasks. Sometimes the level of abstraction and complexity must be reduced for learning purposes.

Role of the teacher: The way of coaching by the teachers has a directing influence on the learning of the student. This refers to the role of the teachers within the authenticity of the community of practice of the entrepreneur.

Facilities and infrastructure: In accordance with what is needed for the execution of the tasks, and for the learning effects, facilities and infrastructure have to be available for students.

Assessment: A high degree of similarity between the assessment of students' tasks and the conditions of assessment in practice are important, and directs the students' learning. Jonassen ${ }^{15}$ identified the critical features of tasks for higher order learning: the type of problem, the degree of complexity and structure. Authentic elements often add to the complexity of the task, and the level of complexity can be adjusted to the adequate level of competence in the learning process of the students. Furthermore the challenge involved in the task appears to be an important factor which influences the students' approach to the task. The authenticity of the task can contribute to this challenge ${ }^{16}$. Schön ${ }^{17}$ notes that "problems in the real world do not present themselves to practioners as well-formed structures... but as messy, indeterminate situations". Ten Berge et al ${ }^{8}$ summarizes the characteristics of the authentic task as the degree of complexity, structure, authenticity and challenge. Tacit knowledge is essential for solving real world problems.

In an authentic learning environment students acquire specific knowledge and skills that are related to the tasks performed. By working on meaningful, and multidisciplinary tasks students learn to integrate skills and knowledge from more than one domain. Because of the situated character of this knowledge and skills, transfer to similar other situations will be better. An authentic learning environments gives the student the opportunity to participate in the discourse of entrepreneurs, and thereby becoming familiar with the culture and language of entrepreneurial life. By working on real-life problems students construct knowledge themselves instead of reproducing knowledge. They are part of a community of practice, where knowledge and meaning is constructed together with others, expressing and discussing their ideas. Also students learn to recognize resources and use them in an effective way. And students acquire tacit knowledge that can only be obtained in practical situations.

\section{Learning context of entrepreneurs}

Professional contexts in which entrepreneurs are operating, are characterized by complexity, time-pressure, deadlines, uncertainty, playing several roles, with multidisciplinary, open-ended, unstructured, hidden and undefined problems, and ambiguous conditions. The learning of the small business owner is characterized by learning from peers, learning by doing, learning from feedback, learning by copying, learning by experiment, learning by problem solving and opportunity taking and learning from mistakes ${ }^{18}$. In these circumstances entrepreneurs learn from collaborating with a diversity of persons in their professional and personal environment: clients, suppliers, competitors, family and friends, bankers and many others. Entrepreneurs learn in multiple, overlapping communities of knowledge and practice, in which they participate. 
Learning from others in the professional and private environment is one of the characteristics of the learning of entrepreneurs. Partners play an important role in reflection and learning of the entrepreneur, as well as in the emotional conflicts that are connected with entrepreneurship ${ }^{18}$.

Baron ${ }^{6}$ has outlined the working situation of entrepreneurs by high levels of uncertainty, novelty, emotion and time-pressure. Cognitive processes of the entrepreneur will be influenced by various forms of bias and error, if an overload of information occurs, and high degrees of uncertainty in new situations occur, in which the entrepreneur cannot fall back on existing mental frame works. Besides that emotions run high, and often high time-pressure exists. These factors from the professional context of the business owners are influencing their cognitive functions, and will cause errors in decision making. Cope ${ }^{19}$ describes that especially critical incidents in the professional life of the entrepreneur evokes high-order learning. Emotions intensify the effects of critical incidents. Nonroutine situations force the entrepreneur to question their taken-for-granted beliefs and assumptions and to reframe their mental frameworks, changing the management of their enterprise, as well as one's personal beliefs and feelings. Essential for learning from critical incidents is deep reflection. Volberda ${ }^{20}$ uses the concept of turbulence- ranging from stable to extreme competition- when analyzing the dynamics, complexity and unpredictability of the market, in which entrepreneurs operate.

Many of the authentic aspects from the complex and unpredictable context of entrepreneurship are not available in default educational circumstances at universities. It is the challenge to create a learning environment that has the characteristics of the entrepreneurial profession to encourages students to entrepreneurial behavior. Application of the design features for authentic learning environments in entrepreneurship, may help to simulate the professional situation, and create a learning environment that focuses on the relevant competences. However, students can not be exposed to "too risky and unsafe" conditions, and the authenticity of certain tasks may have to be reduced to prevent students from (financial) risks they cannot bear responsibility for, and from situations they are not yet able to handle.

\section{Competences of entrepreneurship}

For our purpose we used the definition of competences by Spencer and Spencer ${ }^{21}$ which combines several entrepreneurial elements : 1) motives and intentions, 2) attributes, 3) self-concept (attitudes), 4) knowledge and 5) skills. These elements aim at the performance of specific professional tasks which take place in specified contexts. This definition assembles many of the elements from entrepreneurial theoretical perspectives. It is accepted that knowledge and skills can be learned and can be taught; the self-concept is changeable, however with large strains; and attributes are open to change and can be changed by educators by influencing thoughts, feelings and behavioral intentions $^{22}$. Motives and intentions are linked to the personality of the student, but can be influenced by the ecology of learning: such as the kind and relevance of tasks, and the role of the teacher. In competence based learning all these aspects are considered as a whole, necessary for performing a professional task. Competencies are changeable and learnable, and interventions in terms of education can contribute to this process. 
Motives and intentions select and direct the behavior towards specific goals. Motives of entrepreneurs for starting a venture were first given by Hornaday ${ }^{23}$. It is supposed that motivation is part of the personality of an individual, and motives can become manifest by external factors, and stimulate the individual to action ${ }^{24}$. Driessen ${ }^{25}$ distinguished internal and external factors in the motivation of entrepreneurs. Internal factors are the need for autonomy, the need for achievement and the need for power ${ }^{26}$. External factors are unemployment, seeing a niche in the market, desire to perform the profession or the certainty of having clients. The external factors are in accordance with the definition of entrepreneurship by Bull ${ }^{1}$.

In literature many attributes have been mentioned: endurance, creativity, risk-taking propensity, autonomy, and internal locus of control, self-belief and self-confidence 27,28 . Other attributes are the identification and seizing of opportunities, and the entrepreneurial drive. Attributes may add to the success of the entrepreneur.

The self-concept consists of the set of attitudes, values en convictions of a person. An attitude is generally understood as a learned predisposition to respond in a predictable manner with respect to the object of that attitude ${ }^{29}$. Entrepreneurs show a preference for learning trough action. Preference for innovation, nonconformity, proactive disposition, self-efficacy and achievement motivation were given as attitudinal dimensions of entrepreneurial drive ${ }^{22}$.

Knowledge goals of entrepreneurship education programs have been analyzed by Béchard and Toulouse ${ }^{30}$. They describe eight groups of specific teaching objectives for entrepreneurship education, and distinguish content, skill and situational levels, where the situational level mostly approaches the definition of competences. For entrepreneurial academics research objectives should be added to this list.

Specific entrepreneurial skills are: negotiation, persuasion, selling, proposing, project management, time management, formulating strategy and creative problem solving ${ }^{27}$. Also specific skills for academics should be added to this list.

These five elements above can be combined in logical clusters of competencies, directed by the specific professional tasks of the entrepreneur. As a conclusion students must attain a set of competences, to deal with the specific context of entrepreneurial life, as proposed by Man et al ${ }^{31}$ :

- opportunity competencies: recognizing and developing market opportunities through various means;

- relationship competencies: person-to-person or individual-to-group-based interactions, e.g., building a context of cooperation and trust, using contacts and connections, persuasive ability, communication and interpersonal skills

- conceptual competencies: different conceptual abilities which are reflected in the behavior of the entrepreneur, e.g. decision skills, absorbing and understanding complex information, risk-taking, and innovativeness

- organizing competencies: organization of different internal and external human, physical, financial and technological resources, including team-building, leading employees, training, and controlling

- strategic competencies: setting, evaluating and implementing the strategies of the firm

- commitment competencies: entrepreneurial drive to move ahead with business 


\section{Design principles}

Based on the theory of authentic learning, a set of design principles were deduced for a course on entrepreneurship in ICT at Utrecht University. A design principle is deduced from the knowledge that is generated in design research. Design principles are not intended as recipes for success, but to help others to select and apply the most appropriate substantive and procedural knowledge for specific design and development tasks in a specific setting. Design principles can be formulated according to the heuristic described by McKenney ${ }^{9}$ :

If you want to design an intervention $X$ (for purpose/ function $Y$ in context $Z$ ); then you are best advised to give that intervention the characteristics $C, C, \ldots, C$ (substantive emphasis); and do that via procedures $P, P, \ldots, P$ (procedural emphasis); because the theoretical arguments $T, T, \ldots, T$; and empirical arguments $E, E, \ldots, E$.

Seven design principles for entrepreneurial education for ICT graduates were formulated:

In the design of education with the goal of preparing science students at university

(Z) level for entrepreneurship $(Y)$ :

1. The working atmosphere(X1) should resemble the culture in a small ICT company $(C 1)$, with lots of autonomy $(C 2)$ and responsibility $(C 3)$ for participants and high expectations on their achievements $(P 1)$. If students have ownership $(P 2)$, informal cooperation with others $(P 3)$, and experience time pressure (P4)), they will learn the domain language(T1)culture and tacit knowledge of entrepreneurship(T2), and acquire commitment competencies(T3).

2. The student must be brought in the role of problem solver of real-life problems(X2), working and making decisions autonomously(P1) about products and procedures for solving the problem(P2), and in teams of shared responsibility (P3), because of better transfer $(T)$ and developing problem solving capabilities $(T)$ and the acquisition of domain specific knowledge and skills $(T)$ and obtaining of conceptual competencies $(T)$.

3. The sort of problems and activities(X3) must be realistic in their demands of the market(C1), complexity(C2), structure(C3), challenge(C4), the degree of being open-ended(C5) and being dependent of others' expertise(C6), because of positive effects on transfer to later professional situations in entrepreneurship $(T)$, on the development of effective entrepreneurial behavior(T) and on developing opportunity, strategy and relationship competencies $(T)$.

4. The role of the instructor(X4) should resemble the behavior of a professional entrepreneur(C1)by having the role of co-worker $(P 1)$ or manager $(P 2)$, thereby focusing on coaching students $(P 3)$, because of the stimulating effect of role models on learning $(T)$, and the instructor should avoid taking the role of the expert(P2), because it may obstruct students in autonomous discovery and knowledge construction $(T)$. By this instructor role students will acquire commitment, relational and organizing competencies $(T)$;

5. The facilities and infrastructure(X5) like information systems $(P 1), I C T(P 2$, resources( $(P 3))$ and accommodation $(P 4)$ must be comparable with professional situations so that student learn to recognize and use the resources available $(T)$ and acquire opportunity competencies $(T)$; 
6. assessments(X6) must be performed according to criteria $(C 1)$ and by persons as in entrepreneurship $(C 2)$, so involve clients $(P 1), \quad$ bankers $(P 2)$, entrepreneurs(P3), the market(P4), financing(P5) and competition(P6), and use criteria of the market(P7), and, because of the positive effect of (peer)feedback from the environment(T1) and the effect we expect on relational competencies(T2), such as negotiation, presentation and o the learning process and motivation $(T)$.

7. Students should have multiple roles, as occurring in a company(X7)by having students work at different levels in the organization of the virtual company $(C)$, where they have activities and tasks as a starting entrepreneur $(P 1)$ and as an employee in one of the departments of a company (finance, HRM, facilities, etc) (P2). In this way students learn to work in several and sometimes conflicting roles $(T)$, often multitasking $(T)$, and students will develop organizational and relational competencies $(T)$.

In the set of design principles empirical evidence is not mentioned. This study is a pilot for the empirical verification of the design principles, as they were drafted in this study, and the empirical results will be discussed later. (T) refers to the theory that was discussed in section 2-4 in this paper.

\section{Method}

Design research is based on an iterative cycle of making a design, doing experiments on aspects of the design, next analyzing the results and reflecting on them, and gaining insight in problems and solutions. With each cycle the design of the subject in study can be improved ${ }^{9}$. Outcomes of design study can be a set of (adjusted)design principles, products ( learning materials, a syllabus, software, tasks, cases, etc) and professional development(of instructors and developers).

The design principles drafted in section 5 were evaluated in a course on entrepreneurship in ICT in 2005 and 2006 at Utrecht University, in the Netherlands. It is a graduate course for students in Business Informatics. The course design was developed for approximately 15 students at the maximum. Because the number of attendants was 57 , and because of the number of instructors available, the participants were split up in three business units, within the virtual company Netherware, each business unit consisting of five or six teams each starting a company around a product or service in ICT. The effects of this up-scaling have been reported by $\mathrm{Nab}^{32}$.

In this study the perception of students on the design was measured by using questionnaires with questions related with the learning effects and the course design. Likert-scale items were used as well as open questions. Beside class observations of activities and the mid reviews and end reviews were made. Interviews were held with focus groups of students at the end the course. The results were reported to the main instructor, and several recommendations for the improvement of the next edition of the course were discussed.

\section{Implementation of design principles}


The seven design principles of authentic learning tasks were used to model a course in entrepreneurship in IT products at Utrecht University. In the course various elements were admitted which are in line with the work in practice of the IT entrepreneur. In this study a set of design features was used to describe the intended curriculum and data about the implemented and attained curriculum were collected ${ }^{33}$.

In the course students work on whole, authentic tasks. Students work in small teams on the development of a prototype of a software product, and on a business plan, which aims at bringing this software product into the market. Besides that students have an active role in one of the horizontal teams of the virtual company Netherware

www.netherware.nl), which functions as a holding company for the starting enterprises. Their tasks for the virtual holding may concern HRM, technology, marketing, investor relations, project office, or finance.

\section{Results}

The course and the outcomes (effects in starting enterprises, learning effects, and perception of the course by students) were evaluated and analyzed. The relevance of the course, as perceived by the respondents (67\% of 57 participants), was high (4.21 on a five-point Likert scale). $90 \%$ of the attending student successfully finished the course, meaning they met the competences. In the course of 2005-2006 9 out of 17 companies had plans to enter the market, and continued in an incubator facility that was offered after the course. The collected data were used for analyzing the design principles (see section 5 ) in entrepreneurship education ${ }^{14,32}$.

- Working atmosphere

Activities to create a working atmosphere of a starting IT company were highly appreciated, in particular the social activities as a business dinner and drinks, and presenting Netherware at an innovation fair. These social activities contributed to cooperation. Less effective in the design of the course was the large number of deadlines and deliverables obligated by the holding, which decreased the feeling of autonomy and ownership. Working in the virtual holding did not give the students the impression of working in a real software company. Some students experienced the environment as unorganized. As a conclusion it seems that the social part of the design principle (working atmosphere) seems to be effective, however the work assigned to by the virtual holding was not effective. The work atmosphere of the holding (deadlines and deliverables) does not seem to match with the informality and autonomy of working on starting a business. The "unorganized" context was built in deliberately as most startup ventures act in an unorganized manner, but not all students could appreciate the pedagogical meaning of it. This design principle should be maintained, however the procedures $(\mathrm{P})$ in achieving this needs adjustment.

- Student in the role of problem solver Students were strongly motivated by working on their own product and company, where they were making their own decisions. Some activities felt as obligated by the holding. Here again a discontinuity was seen between the activities for the starting company and for the holding. This design principle should be maintained for reasons of motivation and learning, however some procedures $(\mathrm{P})$ in achieving this needs adjustment.

- Type of problems and activities 
Successful elements of the course were the tasks and activities of students. They learned most of thinking about the key issues of their product while writing the business plan, the software production and the presentation of their business plan for a board of entrepreneurs and venture capitalists. Tasks for the virtual holding company were less appreciated, unless these tasks were contributing directly to their own business. Students prefer to focus on their own product and business. Also the lectures were perceived less relevant and not just-in-time by students. The textbook ${ }^{37}$ used was considered not to be very relevant for their activities. Learning from other teams and business units was not stimulated by the course design. Their was no "authentic" need, derived from the tasks, to have contact with other starting companies and units.

As a conclusion all activities related to the nascence of the own company were appreciated. Lectures should be were planned Just-In-Time and relevant for the activity of that moment. This finding might lead to an adjustment of the procedural part $(\mathrm{P})$ of this design principle: make it more just in time and relevant (connected with the need-toknow design principle ${ }^{38}$ ).

- Role of instructor(s)

The instructors were evaluated positively in their role of instructor and CEO of the virtual company, but were not considered to be good role models for entrepreneurship. Most students asked the CEO/instructor for advice. The role models of entrepreneurs in the course, as guest speakers and assessors, were experienced as relevant and good examples by students. From them students learned what it means to be an entrepreneur. Concluding it appears that instructors should stick to the role that is expected, e.g. being an educator. Apparently the role model of entrepreneurs can only be supplied by authentic entrepreneurs. The procedures in implementing this principle must be changed.

- Facilities and infrastructure

Rooms for the business units were not accessible for students all day, and could not be locked, so students did not perceive the rooms as their company space. It was not considered to be a problem, unless the number of working stations (computers) was insufficient. Changing between rooms was not considered to be a problem. Specific software could be purchased by the holding. It may be concluded that facilities and infrastructure have to be available but little importance was attributed to the way in which it was implemented. However we do not know what the effect if this design principle would have been, if it was implemented.

\section{- Assessment}

The assessment was perceived as realistic and strongly motivating. Students prepared themselves very well for the end review and took this event very seriously. Criteria from the market were used in assessment and in formative feedback. Serious business contacts emerged out of this meetings. The feedback of the panel of entrepreneurs was considered valuable, but more time for consultation was desired by the students. There was little involvement of the students in the plans and products of other teams. This design principle seems to be effective in the perception of students. The involvement of peers $(\mathrm{P})$, as in an entrepreneurial context, could be implemented more strongly.

- Multiple roles

Students were performing several roles in both the starting company and the holding. The priority of students was clearly with the starting company and as both functions interfered, tasks for the holding were felt as disturbing. This double competing roles interfered with other design principles above. It may be concluded that this design 
principle is not effective and should be abandoned or that the procedures $(\mathrm{P})$ through which this principle can be achieved has to be changed to a large extend.

\section{Conclusions}

The design principle of having multiple roles seems to interfere with some of the other principles: working for the holding seems to effect the starting of a business. Only if the activities for the holding contribute directly to starting one's own business it will stimulate learning. This is comparable with entrepreneurial life, where activities are focused, and disturbances are avoided.. This principle can be maintained for further investigation but the procedures leading to it, should be adapted.

Most of the principles seems to be effective, however the procedural parts of several design principles ( working atmosphere, role of instructor, sort of problems and activities, assessment and multiple roles) need adjustment. About the design principle with regard to housing (facilities) no conclusions can be made, because this principle was not implemented as intended for logistic reasons, and could not be evaluated.

In discussion with the instructors the following recommendations were made:

1. Focus on the starting companies as the central activity and promote students' ownership of problems in their own company as well as in the holding. If students feel the ownership of their tasks and activities in both functions, they will be motivated and committed to both. Activities for the holding must make a clear contribution to their own starting company.

2. Make students' activities more market driven; this might increase the feeling of reality and commitment to activities, for their own company as well as for the holding.

3. Increase the involvement and communication with other starting teams in the same business unit as well in other business units. Students can learn from others, from feedback of others, and by cooperating and giving feedback at others. By doing so, they will develop a feeling for the quality and feasibility of plans and products. Also competition between business units may increase the involvement in each others products and activities.

4. Increase the involvement of external entrepreneurs; besides their role in the mid and end review, they could have a role as students' coach during the course. Entrepreneurs form a strong role model, that students will learn from. They can give practical consultation, and be helpful in shaping a network of relations.

5. Stimulate autonomy and responsibility at students in organizing their process of starting a company and of learning. For example make students responsible for just-in-time information gathering. Let students decide themselves in what way they organize their activities, of course within clear expectations and criteria from the CEO.

The design principles evaluated in this study have to be adapted, and the recommendations above will be combined with these design principles. The adaptations will be implemented in the course on entrepreneurship in ICT, and in other intended courses in entrepreneurship at Utrecht University.

The overall conclusion of this study is that six of the seven design principles were effective and should be maintained, however the procedures in achieving the principles 
need some adjustments. About one of the principles (facilities) no conclusion can be drawn as the opinions of the students were too mixed.

\section{Discussion}

According to the theory of experiential learning individuals learn from experience ${ }^{34}$, and therefore in entrepreneurship education students should have real-life experiences to learn from. Also authentic tasks in an authentic context are essential for the acquisition of all sorts of knowledge, including tacit knowledge. However, learning takes place not just from the experience, but only if there is reflection over the experience ${ }^{35}$. Reflection has a key role in making the knowledge from experience explicit to the learner ${ }^{17}$. However, entrepreneurs often fail to reflect because of time pressure and changing and pressing circumstances. They show a preference for fast information gathering to solve a problem ${ }^{36}$. To build in reflection as an authentic activity of education, a design principle on reflection in an entrepreneurial context and following research at this principles' effects is needed.

Competence-based learning integrates knowledge, skills, attitude and attributes, necessary to face the experience ${ }^{21}$. In the application of the design principles a authentic learning environment with real-life experiences can be created, that will stimulate the acquisition of competencies. This authentic environment will add to the motivation of the students; they are owners of the problem they work on, and see the relevance of the authentic task. Ownership has proven to be essential in motivating students and providing an authentic need-to-know that stimulates relevant learning activities. Also students will be better prepared for working as an entrepreneur. Problem solving is domain and situation specific: transfer of what is learned will improve. The transfer of skills and knowledge from the classroom to professional situations has proven to be difficult, and context dependant. As entrepreneurship is about handling new situations, students should learn this in authentic situations, so they can make the transfer of skills and knowledge to later profession. A design principle and following studies on the improvement of transfer must help in stimulating transfer skills in students..

The six design principles for authentic tasks ${ }^{8}$ are to a large extend compatible with and may further complete the design criteria as described by Gibb ${ }^{27}$ : (1) creating the "way of life ' of the entrepreneur; (2) the sharing of culture and values; (3) supporting the development of behaviors, attributes and skills; (4) designing the entrepreneurial organization; (5) developing the learning to learn capacity; (6) being sensitive to the demands of different contexts; and (7) adding value to existing ways of learning. In literature few detailed descriptions of educational programs are available, even if the efficacy of these programs are subject of research, it is not always clear what are the activities of students and what is the precise context of learning. An educational program contains many elements ${ }^{9}$ all intended to bring students to that kind of activities from which students are supposed to learn most. The theory of authentic learning, in combination with design research might help to draw up educational programs on entrepreneurship for further research and give some insight in what interventions may help entrepreneurial learning.

The design principles that we started with can to a large extend be maintained, with some adaptations in the procedures. The set of principles may be extended with principles derived from the recommendations. This set of design principles will be applied in new 
courses in entrepreneurship for science graduates, which are in development at this moment. With these new courses we try to achieve a broader population of students from different disciplines. We will investigate what principles can be generalized and what principles have to be removed or adapted if we broaden the population.

According to McKenney ${ }^{9}$ a set of design principles needs to have consistency among it's (curricular) components, harmony between representations (intentions, implementations and attainments) and coherence within the system context (school, teacher and assessment). Further research on these aspects and the synthesis of these principles into a framework for course design (principle solution for educational design) is needed, as soon as a set of design principles for entrepreneurship education will be established In this study we have considered the process of learning. In future other aspects of the designs have to be studied as well. There should be a focus on the measure of specific learning effects by analyzing students' products, and on long-term effects of entrepreneurship education.

\section{References}

1. Bull, I., Willard, G.E. (1993) Towards a theory of entrepreneurship. Journal of Business Venturing, 8, 183-195

2. Stevenson, H.H. \& Sahlman, W.A. (1989) The entrepreneurial process. In P.Burns \& J.Dewhurst (Eds).Small business and entrepreneurship. Basingstoke: McMillan.

3. Gartner, W.B. (1988). Who is an entrepreneur? is the wrong question. American Journal of Small Business, 13 (1), 11-32

4. Rae, D. (2000) Understanding entrepreneurial learning: A question of how? International journal of Entrepreneurial Behaviour and Research, 6(3), 145-159

5. Mitchell, RK; Busenitz, L; Lant, T; McDoughall, PP; Morse, EA; Smith, JB (2002), Toward a theory of entrepreneurial Cognition: Rethinking the people side of entrepreneurship research. Entrepreneurship Theory and Practice, 27(2), 93-104

6. Baron, R.A.(1998), Cognitive mechanisms in entrepreneurship: why and when entrepreneurs think differently than other people. Journal of Business Venturing, 13, 275-294)

7. Lathi, R.K. (1999). Identifying and integrating individual level and organizational level core competencies, Journal of Business and Psychology, vol. 14, nr 1, 59-75

8. Berge, J.H. ten, Ramaekers, S., Brinkkemper, S., Pilot, A., \& Nab, J. (In preparation) Teaching entrepreneurship in the software branch: the design of an authentic task in higher education. Education and Information Technologies.

9. McKenney, S., Nieveen, N. en Van den Akker, J., (2006). Design research from a curricular perspective. Van den Akker, J., Gravemeijer, 
K., McKenney, S. \& Nieveen, N. (Eds), Educational design research, Routledge, London and New York, p 67-90.

10. Gobert, J.D. \& Pallant, A. (2004) Fostering Students' Epistemologies of Models via Authentic Model-Based Tasks. Journal of Science Education and Technology 13(1): 7-22

11. Brown, J.S., Collins, A., \& Diguid, P. (1989). Situated cognition and the culture of learning. Educational Researcher 18 (1), 32-41

12. Carlson, R.A., Khoo, H., \& Elliot, R.G. (1990). Component practice and exposure to a problem solving context. Human Factors (32): 267-286

13. Shin, N., Jonassen, D.H. \& McGee, S. (2003). Predictors of wellstructured and ill-structured problem solving in an astronomy simulation. Journal of Research in science teaching 40(1): 6-33

14. Berge, H. ten, Nab, J., Pilot, A., \& Ramaekers, S. (2006). Authentic tasks in higher education: Studies in design principles for higher order learning. In: G. Nickmans, M. Bosmans, \& L. Brants (Eds), Improving quality in teaching and learning: Developmental work and implementation challenges (pp 13-15). Leuven: European Association for Research on Learning and Instruction (EARLI).

15. Jonassen, D.H. (2004). Learning to solve problems: An instructional design guide. San Fransisco, CA, Pfeiffer.

16. Cumming, J.J. \& Maxwell, G.S. (1999), Contextualizing Authentic Assessment. In: Assessment in Education: Principles, Policy \& Practice.

17. Schön, D.A. (1987) Educating the reflective Practitioner, Jossey-Bass, San Fransisco, MA.

18. Gibb, A.A. (1997) Small firms' training and competitiveness: building on small business as a learning organization. International Small Business Journal, 15(3), 13-29

19. Cope, J. (2005) Toward a dynamic learning perspective of entrepreneurship, Enterpreneurship Theory and Practice 29(4), 373-397

20. Volberda, H. (2004) De flexibele onderneming: strategieën voor succesvol concurreren. Kluwer, Deventer, p233.

21. Spencer, L.M., \& Spencer, S.M. (1993). Competence at work. Models for superior performance. New York: Wiley \& Sons.

22. Florin, J., Karri, R., and Rossiter, N. (2007). Fostering Entrepreneurial Drive in business Education: An attitudinal Approach. Journal of Management Education 31 (1), 17-42

23. Hornaday, J.A. (1982) Research about living entrepreneurs, in : Encyclopedia of Entrepreneurship, 20-38, Englewood Cliffs, New Jersey.

24. Boekarts, M., \& Simons, R.J. , (1995). Leren en instructie, Van Gorcum, Assen

25. Driessen, MP (2005) E-Scan Ondernemerstest. Beoordeling en ontwikkeling ondernemerscompetentie. PhDThesis, Rijksuniversiteit Groningen, Groningen 
26. Mc Clelland, 1961

27. Gibb, A.A. (2002), Creating conducive environments for learning and entrepreneurship. Industry \& Higher Education, 16(3), 135-148

28. Caird, S.P. (1993). What do psychological tests suggest about entrepreneurs? Journal of Managerial Psychology, 8 (6), 11-20

29. Azjen, I. (1991) The theory of planned behavior. Organisational Behavior and Human Decision Processes 50(2), 1-63.

30. Béchard, J.P. \& Toulouse, J.M. (1998) Validation of a didactical model for the analysis of training objectives in entrepreneurship, Journal of Business Venturing, 13, 317-332.

31. Man, T.W.A., Lau, T., \& Chan, K.F. (2002) The competiveness of small and medium enterprises. A conceptualization with focus on entrepreneurial competencies, Journal of Business Venturing 17(2), 123142

32. Nab, J., Brinkkemper, S., Ten Berge, J.H. \& Pilot, A. (2006) . Netherware: the effects of a synthesis of a course, incubator and coaching facility. In D. Remenyi (Ed.), Proceedings of the European Conference on Entrepreneurship and Innovation (pp. 143-150). Reading, UK: Academic Conferences Limited

33. Van den Akker, J., (2003), Curriculum perspectives, : (Eds), J. van den Akker et al. (Eds), Curriculum Landscape and Trends, Kluwer Academic Publishers, Dordrecht, Boston, London, pp1-10

34. Kolb, D.A. (1984) Experiential learning: Experience as the source of learning and development. Prentice Hall, Englewood Cliffs NJ

35. Arievitch, I.M., \& Haenen, J.P.P., (2005) Connecting socio-cultural theory and educational practice: Galperin's approach. Educational Psychologist, 40(3), 155-165.

36. Sexton, D.L., Upton, N.B., Wacholz, L.E. \& McDougall, P.A. (1997) Learning needs of growth-oriented entrepreneurs. Journal of Business Venturing 12, 1-8

37. Micheal Cusumano: The Business of Software, Free Press.

38. Bulte, A.M.W., Westbroek, H.B., De Jong, O., \& Pilot, A. (2006). A research approach to designing chemistry education using authentic practices as contexts. International journal of Science Education 28(9), 1063-1086

39. Berge, H. ten, Ramaekers, S., Brinkkemper, S., \& Pilot, A. (2005). An authentic task in an informatics course in higher education. In Proceedings of the EARLI conference. Nicosia, Cyprus.

40. Berge, H. ten, Pilot, A., Brinkkemper, S., \& Ramaekers, S. (2005). Ondernemerschap aanleren in een fictief bedrijf bij informatiekunde. In M. Valcke, K. De Cock, D. Gombeir \& R. Vanderlinde (Eds.), Meten en onderwijskundig onderzoek (pp.369-371). Gent: Universiteit Gent Vakgroep Onderwijskunde. 